\title{
Changes in otolith microchemistry over a protracted spawning season influence assignment of natal origin
}

\author{
Geoffrey S. Cook* \\ Integrative Oceanography Division, Scripps Institution of Oceanography, La Jolla, California 92093-0208, USA
}

\begin{abstract}
Our understanding of the role dispersal plays in marine population dynamics is incomplete. One method used to quantify movement among populations is otolith microchemistry. A challenge with this method is gaining an understanding of the spatial and temporal variability of microchemistry that occurs over the course of a protracted spawning season. High-resolution sampling was used to explore the variability of elemental fingerprints of Hypsypops rubicundus at 6 rocky reefs spanning the southern California (USA) coastline from 3 June to 2 September 2008. Otolith microchemistry of 1101 larval fish and 72 juveniles was analyzed using a laser ablation inductively coupled plasma mass spectrometer. Within-reef elemental fingerprints were more similar than among-reef elemental fingerprints. The primary elements enabling discrimination among reefs and their relative contribution (\%) to the elemental fingerprint of each reef were U $(47 \%), \mathrm{Pb}(31 \%), \mathrm{Ba}(14 \%), \mathrm{Mg}$ $(9 \%)$, and $\operatorname{Sr}(1 \%)$. The 2 elements with the most consistent shifts in elemental chemistry from the onset to cessation of the spawning season were Ba (decreased across all study sites) and U (increased across all study sites). More than a third of the time (34\%), the elemental fingerprint of a given reef was indistinguishable from the elemental fingerprint of a different reef later in the spawning season. When natal origins of juveniles were classified using microchemical data spanning the entire spawning season, the number of source populations and number of individuals predicted to have originated from actual source populations were underestimated. Researchers must utilize natural history information together with otolith microchemistry data to ensure that the natal origin of juveniles is assigned using data that account for both spatial and temporal changes in reef-specific elemental fingerprints.
\end{abstract}

KEY WORDS: Connectivity · Dispersal $\cdot$ Temporal variability · Otolith chemistry $\cdot$ Natal fingerprint . Pomacentridae

\section{INTRODUCTION}

In light of pressures currently facing the marine environment, resource managers and policy makers are in need of methods that simultaneously protect marine biodiversity and move fisheries toward sustainability. One of the tools frequently used to achieve these management goals is the creation of marine protected areas (MPAs). However, to create successful MPAs, and MPA networks (i.e. MPAs connected via migration and/or larval dispersal), resource managers need empirical data describing the connectivity of populations on management-relevant time scales (i.e. 1 to $5 \mathrm{yr}$ ). Over larger spatial and temporal scales, advances in molecular methods and large-scale physical oceanographic models have shown promise (see Cowen et al. 2007 and references therein), but one of the most promising techniques for quantifying the connectedness of fish populations on ecological time scales is otolith microchemistry (Thorrold et al. 2007).

Use of otolith microchemistry to quantify population connectivity is a 2-stage process. First, it is necessary to 
ensure there are spatial differences in the reference 'elemental fingerprints' imparted to otoliths developing within larval fish at the study sites of interest (for a recent review, see Thorrold et al. 2007). Second, to examine connectivity, it is necessary to capture individual fish after the pelagic dispersal phase and compare their natal chemical signatures to the reference chemical fingerprints. The natal origin of a postdispersal fish can be inferred by using algorithms to compare otolith core signatures (i.e. the natal portion) of juveniles to the chemical reference data generated from larval fish otoliths collected at known locations earlier in the spawning season.

Early chemical fingerprinting research focused on connectivity in discrete locations and time periods (e.g. Swearer et al. 1999). However, recognition of variability inherent in microchemistry led to multi-year studies searching for stability between years. At this point, many studies have examined the interannual stability of otolith microchemistry in diverse geographic regions (e.g. Channel Islands, Warner et al. 2005, Standish et al. 2008; Gulf of Mexico, Patterson et al. 2008; Hawaiian Islands, Ruttenberg et al. 2008; southern California, USA, Fodrie \& Levin 2008; Galapagos Islands, Ecuador, Ruttenberg \& Warner 2006; Victoria, Australia, Barbee \& Swearer 2007). These studies have met with varied success in finding interannual stability in chemical fingerprints in island settings and along open coastlines. Some have shown that otolith microchemistry can be used to assess population connectivity over 10s of kilometers within a given year (Warner et al. 2005). However, as one moves to larger spatial scales (i.e. 100s of kilometers), variation in geographic locale and natural history of the study species may influence the success of this method. On this larger spatial scale, otolith microchemistry is most successful with diadromous species, where freshwater imparts an identifiable chemical signature to otoliths (e.g. Barbee \& Swearer 2007, Clarke et al. 2009, Walther \& Thorrold 2009). Successful application of this method in other systems has been challenging because of a lack of consistency in chemical fingerprints resulting in lower classification success and reduced confidence in inferred patterns of population connectivity (e.g. with a Hawaiian Island reef fish, Abudefduf sordidus; Ruttenberg et al. 2008). To infer patterns of connectivity successfully, these and other studies have suggested a need to match the life history and scale of larval dispersal distance with the spatial and temporal scale of variability in otolith microchemistry (Ruttenberg \& Warner 2006, Ruttenberg et al. 2008, Walther \& Thorrold 2009).

Elemental fingerprinting applications must contend not only with the spatial variability in otolith chemistry, but also the natural variability in chemical signatures over time. Understanding how otolith microchemistry temporally varies is critical for accurate interpretation of otolith-derived population connectivity estimates. Temporal variation in water chemistry can occur on decadal, interannual, or shorter time scales. An ability to recognize changes in the elemental fingerprint of a given reef over the course of a protracted spawning season has not been examined in detail. Commonly, young-of-the-year (YOY) fish are collected at a given location, and an otolith-derived chemical reference map generated from larval fish collected during 1 segment of a protracted spawning season is used to infer YOY natal origin. Usually the assumption is made that elemental signatures imparted to larval otoliths do not change over the course of the spawning season. If such change occurs, however, the chemical reference map used may incorrectly classify a recruit as originating at one location, when in reality it was spawned at a different location. To infer patterns of population connectivity using elemental fingerprinting, one must ensure that dispersing fish are classified against the appropriate chemical reference map (Walther \& Thorrold 2009).

There is a paucity of data available to address the uncertainty of connectivity estimates associated with intra-seasonal variability of otolith microchemistry (i.e. chemical fingerprint data spanning a protracted spawning season, but see Hamer et al. 2003 or Becker et al. 2005 for an invertebrate example). Hamer et al. (2003) found little intra-annual variability in otolith microchemistry over a 2 mo period, while Becker et al. (2005) found relatively high stability in weekly-scale chemical fingerprints derived from Mytilus mussel shells collected over a $4 \mathrm{wk}$ period from 26 January to 21 February 2002. Many demersal species exhibiting a bipartite life cycle spawn over an extended period of time (i.e. several months), with lengthy planktonic durations. In the present study, I investigated whether intra-seasonal temporal changes in elemental chemistry may confound the interpretation of natal origin in an eastern Pacific temperate damselfish.

This study, spanning the entirety of a 12 wk spawning season, enables the first in-depth examination of intra-annual temporal stability of otolith microchemical signatures. It highlights the value of high-resolution temporal sampling to infer spatial patterns of connectivity among populations inhabiting discontinuous rocky reefs by examining otolith microchemistry across a protracted spawning season. The inherent variability in chemical signatures of larval fish otoliths is quantified over the 3 mo spawning season of garibaldi Hypsypops rubicundus, a rocky reef damselfish inhabiting waters of the Southern California Bight, USA. Otolith microchemistry data were assessed on bi-weekly time scales over 3 spatial scales: (1) within nest $(<1 \mathrm{~m}),(2)$ within reef (among nests separated by meters to 10 s of meters), and (3) among reefs separated 
by 5 to $65 \mathrm{~km}$. Due to broad environmental changes occurring over the protracted spawning season (e.g. within the study region, mean water temperature at $5 \mathrm{~m}$ water depth increased from $\sim 18$ to $21^{\circ} \mathrm{C}$ from onset to cessation of spawning), I hypothesized (1) that otolith chemical variability among samples collected from different nests at a single reef would not vary significantly at a given point in time, (2) that there would be significant differences in elemental signatures within a study reef over the spawning season, and (3) changes in the otolith chemical signatures, both at the within- and among-reef scales, would increase the complexity and uncertainty inherent in identifying the putative natal origins of post-dispersal phase YOY.

\section{MATERIALS AND METHODS}

Garibaldi as a model species. Damselfish (Pomacentridae) are widely distributed in shallow tropical, subtropical, and temperate waters (Allen 1991). Garibaldi Hypsypops rubicundus, a pomacentrid of the San Diegan biogeographic province, primarily inhabits moderate relief (i.e. $>30 \mathrm{~cm}$ ) rocky bottom habitat from Bahia Magdalena, Mexico, in the south to Point Conception, California, USA, in the north $\left(\sim 24\right.$ to $34^{\circ} \mathrm{N}$; Hubbs 1960, Limbaugh 1964). H. rubicundus is a demersal spawner, a trait present in $\sim 50 \%$ of nearshore fish species of this region (Miller \& Lea 1972, Sikkel 1988, 1989, Allen 1991, Love 1996). Here, 'nearshore' is defined as by Shanks \& Eckert (2005) as: the estuarine, the intertidal, and waters $>30 \mathrm{~m}$ depth for species whose range falls between 30 and $47^{\circ} \mathrm{N}$. In San Diego waters, male $H$. rubicundus tend a filamentous red algae nest between March and September; shortly after water temperatures consistently remain above $16^{\circ} \mathrm{C}$, onset of spawning commences (G. Cook unpubl. data). Females deposit tens of thousands (mean = 129000 , Clarke 1970) of elliptical eggs that remain affixed to the red algal nest by sticky filamentous tendrils; typically spawning begins in mid-May and ends by early September (Limbaugh 1964, Clarke 1970). The otoliths of embryonic fish develop while attached to the benthic nest for approximately $2 \mathrm{wk}$. During this embryonic-developmental period prior to hatching, the otoliths incorporate various trace elements into their calcareous matrix, a process that ultimately enables the identification of a natal elemental fingerprint. Just prior to hatching, the sagittal otoliths of the embryonic fish are $\sim 40 \mu \mathrm{m}$ in diameter along the major axis and $10 \mu \mathrm{m}$ 'thick' (G. Cook unpubl. data). After larval fish hatch from their egg capsules, they spend between 18 and 22 d dispersing in the pelagic realm prior to settling on relatively shallow (i.e. $\sim 5$ to $10 \mathrm{~m}$ ) rocky reefs (Clarke 1970, Moser 1996).
Study region and sample collections. Samples were collected from 6 major rocky reef spawning sites in San Diego County, USA. These sites span $\sim 65 \mathrm{~km}$ of coastline, and in sum comprise over $90 \%$ of the Hypsypops rubicundus population in San Diego County (Fig. 1), a population estimate based on $>650$ demographic transect surveys conducted between 2002 and 2010 (G. Cook \& E. Parnell unpubl. data). Benthic nests were located on rocky reef substrate between 3 and $15 \mathrm{~m}$ water depth. The distance between adjacent sites ranged from as little as $5 \mathrm{~km}$ (i.e. La Jolla and Torrey Pines) to as much as $15 \mathrm{~km}$ (i.e. La Jolla and Mission Point); the nearest suitable habitat/spawning sites outside of the study region are located $35 \mathrm{~km}$ to the south of the southernmost study site, near Rosarito, Baja California, Mexico, and $50 \mathrm{~km}$ north of the northernmost study site, near Dana Point, California. Median depthaveraged water velocities of $<2 \mathrm{~cm} \mathrm{~s}^{-1}$ measured in this region (Rasmussen et al. 2009, L. Rasmussen unpubl. data) suggest that the 6 study reefs span more than

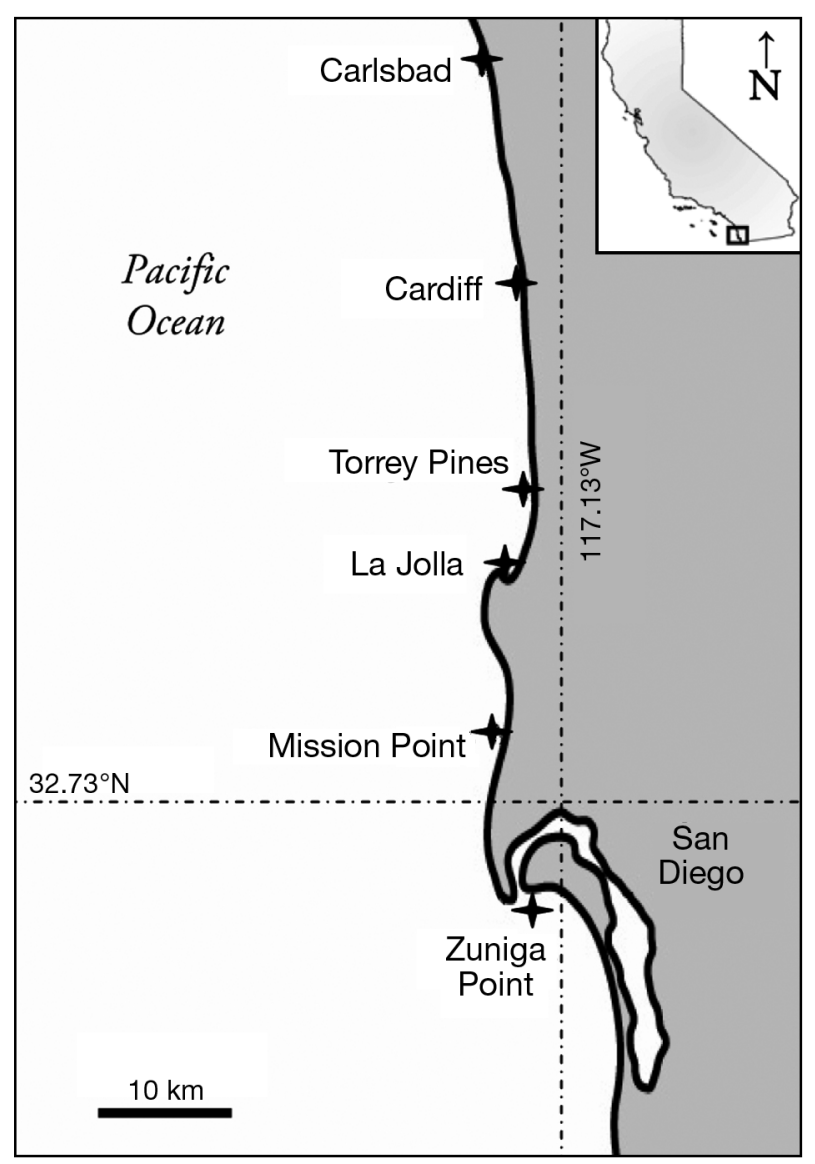

Fig. 1. Study region, including location of 6 study reefs where Hypsypops rubicundus were collected. (1) Carlsbad, (2) Cardiff, (3) Torrey Pines, (4) La Jolla, (5) Mission Point, and

(6) Zuniga Point. Stars indicate location of study sites. Inset shows location of study region within California, USA 
twice the distance a passively dispersing larval fish would travel over an 18 to $22 \mathrm{~d}$ pelagic larval period.

Trends in otolith microchemistry data across the 2008 spawning season are presented for all 6 reefs. Of these reefs, Torrey Pines had the longest spawning season in 2008 (i.e. individual study sites had spawning seasons 4 to $12 \mathrm{wk}$ in duration, Table 1). Using SCUBA, nests were monitored throughout the 2008 spawning season, and biweekly collections of latestage embryos (i.e. those just prior to hatch) were made from 4 subjectively-selected benthic nests on each dive from 3 June to 2 September 2008. Immediately after collection, samples from individual nests were placed on ice, and upon return to the laboratory were placed in acid-washed $50 \mathrm{ml}$ centrifuge tubes and frozen until further analysis.

Larval collections. In total, 32 nests were collected at Torrey Pines; of these, 456 larval fish from 23 nests provided a single sagittal otolith of sufficient size to generate usable trace-elemental data (i.e. otoliths were large enough to be individually extracted, cleaned, mounted, and analyzed). In a similar fashion, benthic nest collections were made from 3 June until 21 August 2008 at the other 5 study reefs, yielding a combined total of 1101 larval fish otoliths from 77 nests across all 6 study sites (Table 1).

Otolith extraction, preparation, and elemental analysis. Most larval fish hatched from collected egg capsules between the time of collection on a benthic nest and the collector's return to the water's surface. Samples were frozen at $-20^{\circ} \mathrm{C}$ prior to processing, and upon thawing, single larval fish were placed in an individual drop of MilliQ water (i.e. quartz-distilled water with resistivity $>18.1 \mathrm{M} \Omega$ ) on an acid-washed slide. A single sagittal otolith was extracted using a finetipped tungsten probe; subsequently, otoliths were transferred among slides using a nasal hair affixed to a wooden dowel (methods developed by Becker et al. 2005 and M. Takahashi, Seikai National Fisheries Research Institute). After this point, any glassware coming into direct contact with extracted otoliths was not acid-washed, but rather rinsed 10 times in MilliQ to prevent dissolution caused by acidic residue remaining on acid-washed slides (S. Koch pers. comm., G. Cook pers. obs.). These otoliths were subsequently moved from a clean laboratory area to a Class 100 (ISO 5) clean room.

To eliminate contaminants and remove organic tissue, otoliths were transferred from the extraction slide to a drop of $15 \% \mathrm{H}_{2} \mathrm{O}_{2}$ buffered with $0.05 \mathrm{~mol} \mathrm{l}^{-1} \mathrm{NaOH}$. They were then sonicated for $5 \mathrm{~min}$, transferred to a single drop of MilliQ, and sonicated for an additional $5 \mathrm{~min}$, then rinsed 3 more times. After the final MilliQ rinse, otoliths were mounted on double-sided tape affixed to petrographic slides, and stored in a Class 100 laminar flow hood located within a Class 100 clean room.

All otoliths were analyzed using a New Wave UP $213 \mathrm{~nm}$ laser ablation unit coupled to a Thermoquest Finnegan Element 2 inductively coupled plasma mass spectrometer (at the University of California Santa Barbara). Three standards were used to ensure proper calibration of the instrument: a solution-based dissolved $\mathrm{CaCO}_{3}$ reference material (OTO), and 2 solid standards, NIST 612 (a commonly used glass standard) and the newly available USGS MACS3 $\mathrm{CaCO}_{3}$ standard. All reference materials, both solution- and solidbased, were analyzed at the beginning and the end of each run; mounting medium and instrument blanks were run multiple times during a sequence.

Based on preliminary testing, ${ }^{24} \mathrm{Mg},{ }^{55} \mathrm{Mn},{ }^{87} \mathrm{Sr},{ }^{138} \mathrm{Ba}$, ${ }^{208} \mathrm{~Pb}$, and ${ }^{238} \mathrm{U}$ were selected for analysis at low resolution. Isotopes were included in subsequent analyses if counts were $>3$ standard deviations (SDs) of background levels when blanks were run. All isotope data are given as concentration relative to ${ }^{48} \mathrm{Ca}$ in either mmol mol ${ }^{-1}$ or $\mu \mathrm{mol} \mathrm{mol}^{-1}$ (hereafter, 'concentration'). For ablations, laser intensity was set at $50 \%$ with a $40 \mu \mathrm{m}$ spot size and a $4 \mathrm{~s}$ dwell time. As larval fish otoliths were relatively small (range $=8.5$ to $44.6 \mu \mathrm{m}$ in diameter), it was necessary to ablate all otolith material

Table 1. Hypsypops rubicundus. Number of nests collected, number of nests and otoliths analyzed, mean $( \pm$ SD) number of otoliths analyzed per nest, range of 2008 spawning season, and number of young of the year (YOY) collected at each reef.

LA-ICPMS: laser ablation inductively coupled plasma mass spectrometry

\begin{tabular}{|c|c|c|c|c|c|c|c|}
\hline Study reef & $\begin{array}{c}\text { Total } \\
\text { nests } \\
\text { collected }\end{array}$ & $\begin{array}{c}\text { Nests } \\
\text { analyzed by } \\
\text { LA-ICPMS }\end{array}$ & $\begin{array}{c}\text { Otoliths } \\
\text { analyzed by } \\
\text { LA-ICPMS }\end{array}$ & $\begin{array}{l}\text { Otoliths } \\
\text { per nest } \\
\text { analyzed }\end{array}$ & $\begin{array}{c}\text { First } \\
\text { collection } \\
\text { date }\end{array}$ & $\begin{array}{c}\text { Last } \\
\text { collection } \\
\text { date }\end{array}$ & $\begin{array}{c}\text { YOY } \\
\text { collected }\end{array}$ \\
\hline Carlsbad & 10 & 8 & 80 & $9.5 \pm 2.5$ & 24 July & 21 August & 18 \\
\hline Cardiff & 12 & 9 & 114 & $10.8 \pm 5.0$ & 10 July & 21 August & 10 \\
\hline Torrey Pines & 32 & 23 & 456 & $19.8 \pm 5.9$ & 3 June & 2 September & 0 \\
\hline La Jolla & 18 & 18 & 212 & $10.9 \pm 4.9$ & 3 June & 29 July & 42 \\
\hline Mission Point & 11 & 8 & 123 & $14.8 \pm 7.0$ & 15 July & 12 August & 1 \\
\hline Zuniga Point & 12 & 11 & 116 & $9.5 \pm 3.0$ & 22 July & 19 August & 0 \\
\hline Total & 95 & 77 & 1101 & & & & 72 \\
\hline
\end{tabular}


Table 2. Estimates of precision (relative standard deviation, $\%$ RSD) for laser ablation inductively coupled plasma mass spectrometry analyses and limits of detection for elements of interest. RSDs were calculated from more than 6500 means of 6 scans (i.e. number of scans per sample), and are presented for a dissolved $\mathrm{CaCO}_{3}$ reference material (OTO), and 2 solid reference materials: NIST 612 and USGS MACS3

\begin{tabular}{|crrrr|}
\hline Element & \multicolumn{4}{c}{ \%RSD } \\
\cline { 2 - 5 } & OTO & $\begin{array}{r}\text { NIST } \\
612\end{array}$ & $\begin{array}{c}\text { MACS } \\
3\end{array}$ & $\begin{array}{c}\text { Detection limit } \\
\left(\mathrm{mmol} \mathrm{mol}^{-1} \mathrm{Ca}\right)\end{array}$ \\
\hline $\mathrm{Mg}$ & 1.03 & 9.50 & 7.68 & 0.04 \\
$\mathrm{Mn}$ & 1.63 & 8.87 & 6.02 & 0.03 \\
$\mathrm{Sr}$ & 2.18 & 8.23 & 4.74 & 0.04 \\
$\mathrm{Ba}$ & 3.22 & 10.01 & 8.93 & 0.31 \\
$\mathrm{~Pb}$ & 4.41 & 10.07 & 8.17 & 0.25 \\
$\mathrm{U}$ & 5.27 & 8.68 & 13.43 & 0.01 \\
\hline
\end{tabular}

during a single ablation; this precluded multiple ablations of the larval fish otoliths and YOY natal core (see below). Estimates of the external precision for standards, given as relative SD (\% RSD) for the various isotopes, and detection limits are given in Table 2 .

YOY collections. In 2008, post-dispersal phase YOY ( $\mathrm{n}=72$ ) were collected from 4 of the 6 study reefs using hand nets. Two reefs, Zuniga Point and Torrey Pines, did not receive any YOY settlers in 2008. The YOY collections occurred from 26 August until 20 November 2008. The sagittal otoliths from these fish were extracted using a ceramic scalpel, and were cleaned, processed, and stored in the same manner as the larval otoliths. However, in the final stage of processing, rather than being mounted on double-sided tape, otoliths were mounted on petrographic slides using cyanoacrylate. Otoliths were polished to within 15 to $30 \mu \mathrm{m}$ of the core using a lapping wheel with $30 \mu \mathrm{m}$ and $3 \mu \mathrm{m}$ diamond polishing film, and prior to analysis cleaned with $1 \% \mathrm{HNO}_{3}^{-}$and MilliQ water. One sagittal otolith was used for microchemical analysis, while the remaining sagittal otolith was used for aging fish by counting daily growth rings. To identify core signatures of the otoliths, 8 consecutive vertical pits each consuming a 'disc' of otolith material approximately $40 \mu \mathrm{m}$ in diameter and $10 \mu \mathrm{m}$ 'thick' were ablated. Ablations over the core region of each otolith were preceded by pre-ablations to remove possible contaminants; the putative core disc was identified by a characteristic Mn spike (Ruttenberg et al. 2005). The microchemical data of the core discs were subsequently compared to the reefspecific chemistry created by the larval fish otoliths to infer the natal origin of the post-dispersal phase YOY fish (see 'Statis- tical analyses' below). Independent seawater samples were not collected as part of this study, as previous work in the region has shown that the elemental chemistry of aragonitic structures (e.g. larval fish otoliths) becomes integrated over periods of multiple days and does not resemble point samples of water collected during the same period of time (Becker et al. 2005, Warner et al. 2005).

Estimates of YOY age were derived by counting otolith daily growth rings using light transmission microscopy. Rings were counted from the edge of putative core regions (identified by measurements of larval fish otoliths) to an outer edge. However, otoliths proved challenging to age unequivocally because of poor light transmission near otolith primordia. To be conservative, YOY were placed within 2 wk bins reflecting the putative 2 wk period when they were developing embryos on benthic nests (Fig. 2).

Statistical analyses. Multivariate outliers were identified using jack-knifed Mahalanobis distances. Univariate outliers (those falling outside of $95 \%$ confidence intervals) were identified by visual inspection, and to be conservative, these otoliths were removed from statistical analyses. All elements violated the univariate assumption of normality (as assessed by the Shapiro-Wilk goodness of fit test, $\mathrm{p}<0.05)$. Natural log-transformed data improved assumptions of normality but qualitatively were similar to untransformed data in parametric univariate and multivariate analyses. Therefore results and significance levels are presented for untransformed data. One-way analysis of variance (ANOVA) was used to examine univariate temporal differences in elemental chemistry at a given study site (i.e. how a given element changed over the spawning season); ANOVA was also used to test for

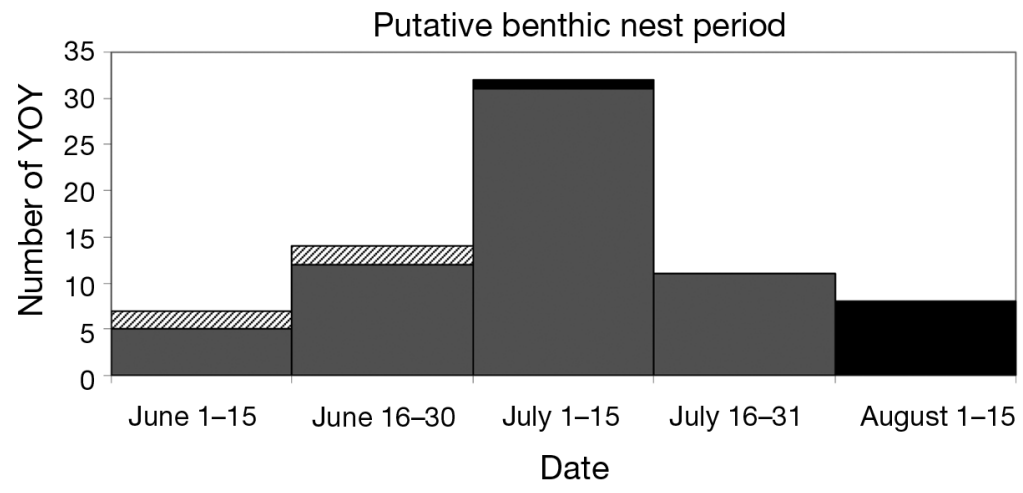

Fig. 2. Hypsypops rubicundus. Putative benthic nest period of young of the year (YOY) collected in $2008(n=72)$. Each 2 wk period is the time period during which the YOY were acquiring their natal elemental signatures. Cross-hatched portions of the histogram indicate the proportion of YOY predicted to have originated from Torrey Pines ( 6\%). Grey portions indicate the proportion of YOY predicted to have originated from La Jolla ( 82\%), and black portions indicate the proportion of YOY predicted to have originated from Mission Point ( 13\%) 
spatial differences in individual elements (among nests within a reef and among reefs during a given segment of the spawning season). Significant results of the omnibus tests were assessed with a Tukey honestly significant difference (HSD) test. Nested multivariate ANOVA (MANOVA) was used to assess temporal and spatial differences in multi-elemental fingerprints. Pillai's trace was chosen as the test statistic to assess significant differences of multi-elemental concentrations, as it is more robust to violations of multivariate normality (Zar 1999). All ANOVAs and MANOVAs were completed using JMP (Version 6.0.3).

To examine the relative influence of temporal and spatial scales on the trace elemental fingerprints, non-parametric multivariate analysis of similarity (ANOSIM) procedures were conducted with otolith microchemistry from individual reefs binned across 3 temporal periods: biweekly, monthly, and over 6 wk (i.e. early versus late spawning season). A post hoc similarity percentages procedure (SIMPER) was conducted to determine which elements were responsible for driving the chemical variability within and between reefs across all temporal scales (Clarke \& Warwick 2001, Clarke \& Gorley 2006).

ANOSIM is a permutation procedure applied to the Euclidean similarity matrix using a calculated R statistic, and in the present study tests the null hypothesis that there is no difference in the chemical fingerprints between 2 reefs (Clarke \& Warwick 2001, Clarke \& Gorley 2006). R ranges from 0 (i.e. otolith chemistry within and between reefs is the same) to 1 (i.e. chemically all otoliths from 1 reef are more similar to each other than to otoliths from a different reef). In this procedure, 10000 permutations were run. Subsequently, the value of $\mathrm{R}$ for the empirical microchemistry data is compared with the distribution of $\mathrm{R}$ derived from the permutation test to calculate a probability that the observed $\mathrm{R}$ statistic is no different than an $\mathrm{R}$ achieved by a randomly generated data set. As p-values are greatly influenced by sample size, results of the ANOSIM are best interpreted by examining R-values. An $\mathrm{R}<0.25$ indicates that reefs are chemically indistinguishable from one another, while an $\mathrm{R}>0.5$ implies that otoliths from reefs are chemically well separated.

To test whether chemical similarity was related to the geographic distance separating reefs or to the length of time between sampling events (i.e. a proxy for when otoliths acquired their natal signatures), the data from the ANOSIM procedures were used to divide the reefto-reef comparisons into 2 groups based upon R-values. To determine whether reefs with more distinct elemental fingerprints have more geographic distance between them and/or more time between sampling events than those reefs with poor separation, a $t$-test was conducted between reef pairs with R-values greater than 0.5 ( $\mathrm{n}=78$, reefs with higher discriminatory ability) and those with
R-values less than 0.25 ( $\mathrm{n}=87$, reefs with lower discriminatory ability). All ANOSIM and SIMPER routines were conducted on natural log-transformed data to compute the Euclidean distance matrix and subsequent dissimilarity matrix using PRIMER Version 6.1.6 (Clarke 1993, Clarke \& Warwick 2001, Clarke \& Gorley 2006).

Linear discriminant function analysis (DFA) was used to test how temporal binning of microchemistry data (i.e. 2, 4, 6, and $12 \mathrm{wk}$ ) influences the prediction of natal origins of YOY. Quadratic DFAs were also performed on these data for comparative reasons; however, these neither resulted in significant differences from linear DFA (i.e. differences in classification success between the 2 methods were less than $1 \%$ ), nor different classification of natal origin of YOY fish. Therefore, results are presented only from the linear DFA. In the DFA classification procedure, larval otoliths were used to create a training dataset, and YOY cores were classified as unknowns against this training set to determine their putative natal origin. To compare the DFA jackknife reclassification success to that expected from a randomly generated data set, 1000 runs were made of randomized data sets. All DFAs and randomization procedures were run in Matlab Version 7.4, modified from White \& Ruttenberg (2007).

\section{RESULTS}

Of the initial 1101 larval fish otoliths, 72 otoliths were removed from subsequent analyses because they fell below detection limits for individual elements (52 for $\mathrm{Pb}, 6$ for $\mathrm{U}$ ) or because they were multivariate outliers $(n=14)$, reducing the total sample size of larval otoliths included in the analyses to 1029. This removal of outliers decreased the total number of clutches analyzed from 77 to 76 (i.e. 1 nest from Torrey Pines was not included in analyses). The median number of otoliths per nest providing usable microchemistry data ranged from 10 to 19 (Table 1). In addition, Mn yielded measureable concentrations in larval otoliths, but consistently fell below detection limits. Therefore Mn data are presented for comparative purposes, but are excluded from multivariate analyses.

\section{Spatial variability of otolith microchemistry}

Within-reef elemental variability

Significant differences were detected in among-nest, multi-elemental chemical fingerprints (MANOVA $\mathrm{p}<$ 0.001), but generally there were no significant differences in univariate elemental concentrations among nests collected at a given reef for a given date. At 
Torrey Pines across the 36 possible 1-way ANOVAs (i.e. 6 elements over 6 dates) spanning the 2008 spawning season, 26 had no significant differences. Two of the elements, Mg and Mn, were never significantly different among nests. Three of the elements, $\mathrm{Sr}, \mathrm{Ba}$, and $\mathrm{Pb}$, had significant among-nest differences on 2 dates, and $U$ was significantly different among nests on 4 of the 6 sampling dates. Upon further review with post hoc Tukey HSD tests ( $p<0.05)$, it was apparent that significant results in element-by-element ANOVAs were attributable typically to 1 nest with a significantly higher or lower concentration of a single element.

\section{Among-reef elemental variability}

Study reefs were separated by distances between 5 and $65 \mathrm{~km}$. At this spatial scale, when otoliths from individual reefs were grouped across the entire 2008 spawning season, reef-specific elemental fingerprints differed significantly from one another (MANOVA, Pillai's Trace $\left.=0.354, F_{25,5115}=15.58, \mathrm{p}<0.0001\right)$. Zuniga Point and Torrey Pines otoliths had significantly higher levels of Mg compared to Cardiff, La Jolla, or Mission Point otoliths (1-way ANOVA, $F_{5,1023}=5.74, \mathrm{p}<0.0001$ ). La Jolla otoliths had significantly higher levels of Mn than those from Carlsbad, Mission Point, or Zuniga Point $\left(1\right.$-way ANOVA, $\left.F_{5,1023}=3.74, \mathrm{p}<0.002\right)$. Levels of $\mathrm{Sr}$ in larval fish otoliths were significantly lower at La Jolla compared to all other sites (1-way ANOVA, $F_{5,1023}=$ 48.44, $\mathrm{p}<0.0001)$; Ba levels were significantly higher at Carlsbad, La Jolla, and Zuniga Point (1-way ANOVA, $\left.F_{5,1023}=5.64, \mathrm{p}<0.0001\right)$. Levels of $\mathrm{Pb}$ were significantly lower in otoliths at Torrey Pines and La Jolla (1-way ANOVA, $F_{5,1023}=3.12, \mathrm{p}<0.008$ ), and $U$ was significantly lower in otoliths from La Jolla and Mission Point $\left(1\right.$-way ANOVA, $\left.F_{5,1023}=23.04, \mathrm{p}<0.0001\right)$.

When elemental fingerprints of reefs were compared for only the period of time when all sites had spawning fish (mid-July to mid-August), reef elemental fingerprints were significantly different (MANOVA, Pillai's Trace $\left.=0.503, F_{25,1835}=8.22, p<0.0001\right)$. Carlsbad otoliths had significantly higher levels of $\mathrm{Mg}$ than did Mission Point otoliths (1-way ANOVA, $F_{5,367}=3.16, \mathrm{p}=$ 0.008), La Jolla otoliths had significantly higher levels of $\mathrm{Mn}$ than those from Cardiff (1-way ANOVA, $F_{5,367}=$ $3.05, p=0.01)$, Carlsbad and Cardiff otoliths had significantly higher levels of Sr than otoliths at all other reefs (1-way ANOVA, $\left.F_{5,367}=29.87, \mathrm{p}<0.0001\right)$, Mission Point and La Jolla otoliths had significantly lower levels of Ba (1-way ANOVA, $\left.F_{5,367}=13.89, \mathrm{p}<0.0001\right)$, and Torrey Pines and Zuniga Point otoliths had significantly higher levels of $U$ when compared against all other reefs. $\mathrm{Pb}$ levels did not differ significantly among any of the reefs (1-way ANOVA, $F_{5,367}=1.00, p=0.42$; Fig. 3 ).

\section{Temporal variability of otolith microchemistry}

Within-reef elemental variability

When individual reefs were examined for temporal changes in elemental fingerprints over the 2008 spawning season, results varied by reef. At Carlsbad, the northernmost site, multi-elemental fingerprints were similar over the 1 mo spawning season in 2008 (MANOVA, Pillai's Trace $=0.148, F_{5,70}=2.07, \mathrm{p}=0.08$ ).

At Torrey Pines (the reef with the most protracted spawning season in 2008), elemental fingerprints changed significantly from early June to early September $\left(\right.$ MANOVA, Pillai's Trace $=0.882, F_{30,2145}=15.32$, $\mathrm{p}<0.0001$; Fig. 4). Three of the elements, $\mathrm{Mg}, \mathrm{Pb}$, and $\mathrm{U}$, increased in relative concentration over the course of the spawning season, while $\mathrm{Mn}, \mathrm{Sr}$, and $\mathrm{Ba}$ decreased (all $\mathrm{p}<0.001$ ). Elemental fingerprints at all other study reefs changed significantly over the course of the 2008 spawning season (MANOVA, Pillai's Trace associated $\mathrm{p}$-values $<0.0001$ for all reefs).

\section{Among-reef elemental variability}

When otolith-derived chemical data from individual reefs were binned across 2, 4, or $6 \mathrm{wk}$, and compared against other reefs, highly significant differences were observed in study reef multi-elemental fingerprints at all temporal scales (MANOVA, Pillai's Trace $\mathrm{p}<$ 0.0001). In a subsequent univariate comparison, relative concentrations of all 6 elements comprising otoliths collected during the first half (i.e. 3 June to 15 July 2008) of the spawning season were significantly different from otoliths collected during the second half of the spawning season (i.e. 16 July to 2 September 2008; all 1 -way ANOVA $\mathrm{p}<0.001$, Tukey HSD $\mathrm{p}<0.05)$. Similarly, at the shortest temporal scale (i.e. biweekly), chemical fingerprints of reefs changed significantly over the course of the 2008 spawning season, in both multi-elemental fingerprints (MANOVA, Pillai's Trace $\left.=1.095, F_{115,5025}=12.25, \mathrm{p}<0.0001\right)$ and individual elements compared among reefs (1-way ANOVA, $F_{23,1005}$ ranged from 3.7 to 29.3, all $\mathrm{p}<0.0001$; all Tukey HSD p-values < 0.05).

\section{Interaction of spatial and temporal variability of otolith microchemistry}

Of the 15 reef-to-reef comparisons spanning the entirety of the 2008 spawning season, none had an R statistic greater than $0.16(p<0.001)$, suggesting that at this temporal scale $(\sim 12 \mathrm{wk})$, the reefs were essentially indistinguishable from a microchemical stand- 

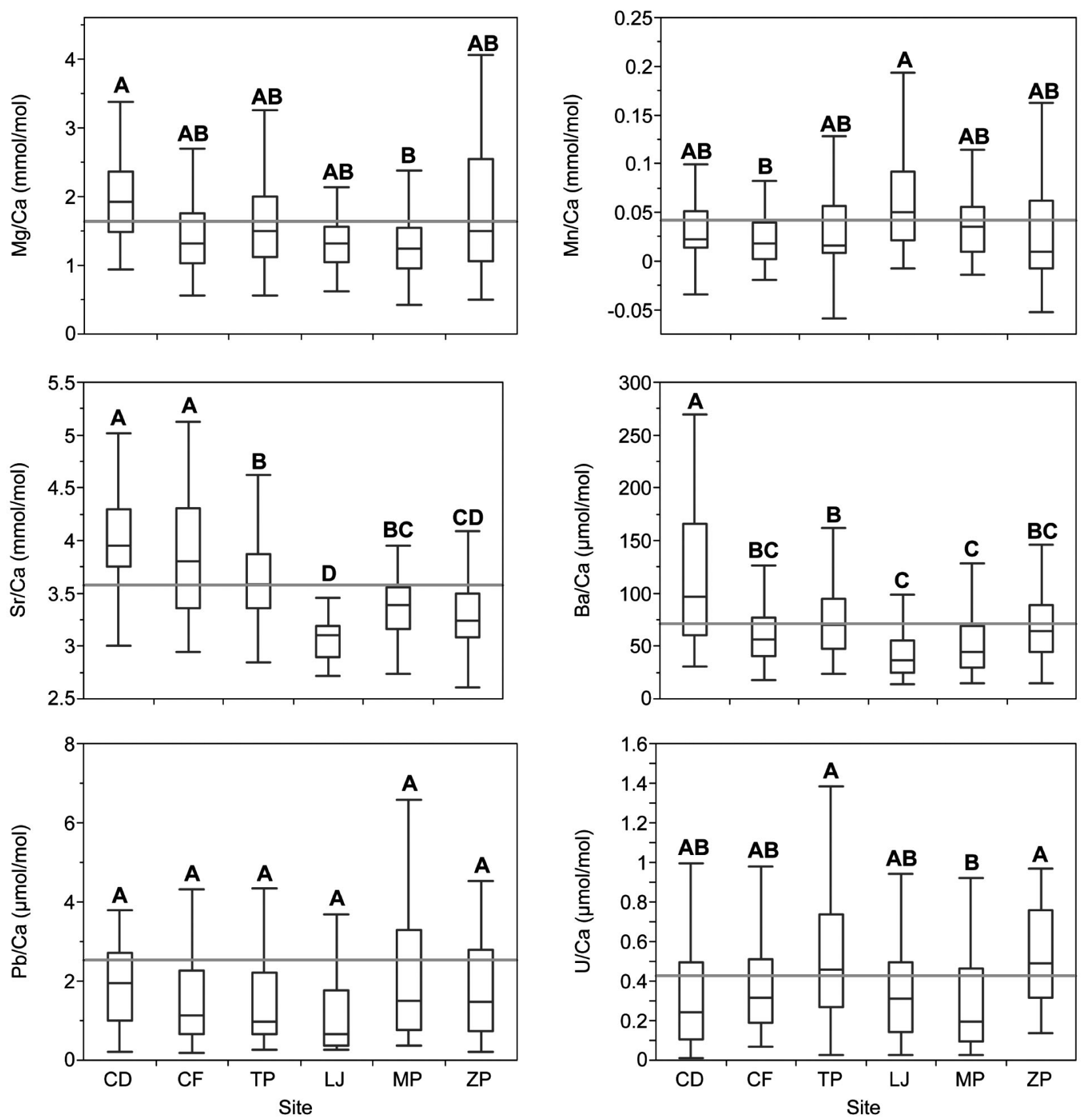

Fig. 3. Hypsypops rubicundus. Inter-reef spatial variability of otolith microchemistry during the period of concurrent spawning (i.e. mid-July to mid-August 2008). Box plots indicate median, 75th, and 25th percentiles; whiskers indicate 95th and 5th percentiles. Nests not connected by similar letters are significantly different (Tukey HSD $p<0.05$ ). Continuous horizontal grey lines indicate the grand mean. CD: Carlsbad, CF: Cardiff, TP: Torrey Pines, LJ: La Jolla, MP: Mission Point, and ZP: Zuniga Point. Note different scales on $y$-axes

point. As the data were broken down to shorter temporal bins, the R-values increased. The highest separation among reefs occurred when data were compared in 2 wk bins indicating that the greatest chemical separation among study reefs occurred at this shortest temporal scale (ANOSIM, R = 0.8, p < 0.0001; Bonferroni corrected value of alpha $<0.05)$.
When chemical fingerprints of individual reefs were assessed at this shortest temporal scale, there were 300 possible reef-to-reef comparisons (including combinations when the elemental fingerprint of 1 reef was compared against itself at a later point in the spawning season). When only distinct reefs were compared, there were 255 reef-to-reef comparisons. In 87 of these 

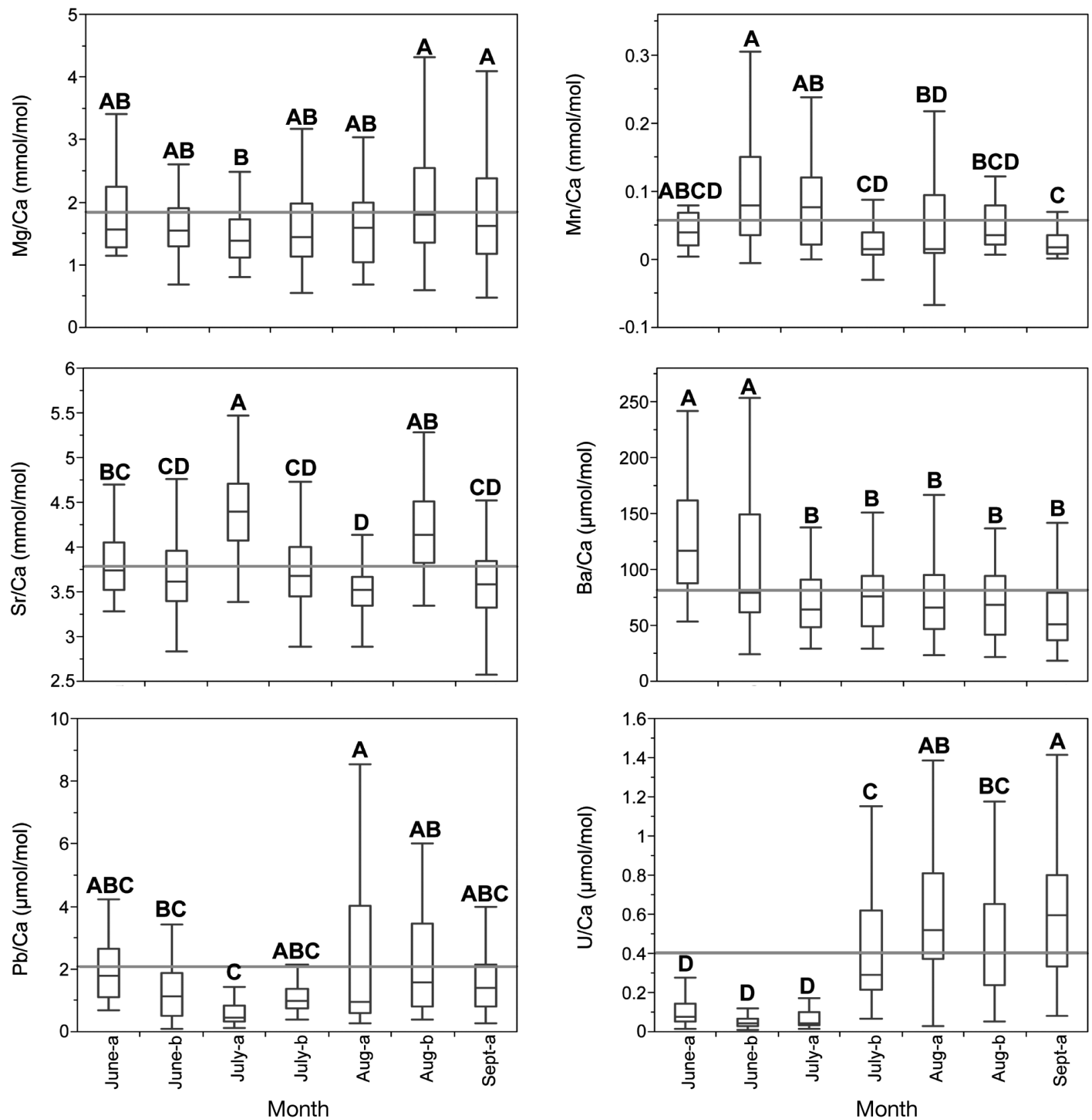

Fig. 4. Hypsypops rubicundus. Temporal variability of otolith microchemistry at Torrey Pines Reef across the 2008 spawning season. Box plots indicate median, 75th, and 25th percentiles; whiskers indicate 95th and 5th percentiles. Two-week bins of time not connected by similar letters are significantly different (Tukey HSD p <0.05). Continuous horizontal grey lines indicate the grand mean. Suffix a (b) after month indicates the first (last) $15 \mathrm{~d}$ of the month. Note different scales on $y$-axes

(34\% of the comparisons), 1 reef was chemically indistinguishable from a different reef at a later segment of the spawning season (ANOSIM, R $<0.25$, p $<0.0001$; Bonferroni corrected value of alpha $<0.05$ for all reefto-reef comparisons). Among these 87 comparisons, the primary elements driving the chemical differences between reefs (and relative contribution of these elements to chemical differences) were $\mathrm{Pb}(46 \%), \mathrm{U}$ $(26 \%), \mathrm{Ba}(17 \%)$, and $\mathrm{Mg}(10 \%)$. There were 78 instances where reef pairs were well separated by otolith microchemistry (ANOSIM, R > 0.5, p < 0.0001, Bonferroni corrected value of alpha $<0.05$ ); all other reef pairs had intermediate ANOSIM R-values. The primary difference between reefs that were chemically well separated and those that were not well separated was in $U$, which accounted for the greatest chemical variability $(66 \%)$, while $\mathrm{Pb}, \mathrm{Ba}$, and $\mathrm{Mg}$ contributed 22,7 , and $5 \%$, respectively. In all comparisons, Sr typi- 
cally accounted for $<1 \%$ of the chemical differences between reefs.

To assess the relative importance of temporal and spatial scale on the ability to discriminate between 2 different reefs, the distance between reefs and the time between otolith collections was compared for reef pairs with low $(\mathrm{n}=87, \mathrm{R}<0.25)$ and high $(\mathrm{n}=78, \mathrm{R}>$ $0.5)$ ANOSIM R-values. In these 2 groups there was no statistical difference in the distance between reefs; on average, $20.6 \mathrm{~km}$ separated reefs with distinct chemical signatures, and $25.4 \mathrm{~km}$ separated reefs with similar chemical signatures (1-way ANOVA, $F_{1,163}=3.37$, $\mathrm{p}=0.07$ ). In a similar comparison, there was a significant difference in the duration of time between sampling, $5.7 \mathrm{wk}$ for chemically distinct reefs and $3.1 \mathrm{wk}$ in chemically similar reefs (1-way ANOVA, $F_{1,163}=59.9$, $\mathrm{p}<0.0001$ ).

\section{Classification of YOY fish}

Discrimination among reefs (using DFA) was most successful (i.e. had highest classification success) when data were analyzed in $2 \mathrm{wk}$ bins (e.g. mean biweekly classification success $=71 \%$ versus $53 \%$ for the entire 2008 season). However, all combinations comparing otolith microchemistry among reefs across all 4 temporal bins (i.e. biweekly to seasonally) resulted in DFA classification success rates significantly higher than classification success rates that would have been observed given a randomly generated data set $(p<0.001)$.

When elemental signatures from YOY fish were compared against the various temporal bins of larval otolith microchemistry data, different natal origins were predicted. Use of larval reference data for the complete spawning season suggested that all but 2 of the 72 YOY collected in 2008 originated at the reef in La Jolla $(\mathrm{n}=$ $70,97 \%$ ); the remaining 2 individuals appeared to have originated from Mission Point. Predicting natal origin of YOY using the chemical reference map generated from the entire 2008 data set, for example, suggests that 7 of 8 individuals that were developing embryos in the first 2 wk of August (based on otolith aging) originated from La Jolla reefs. However, based on empirical survey data, no spawning occurred in La Jolla at this point in time. As YOY microchemistry was compared with larval reference data from shorter periods of time (i.e. closer to the $2 \mathrm{wk}$ bins in which individuals are actually developing embryos acquiring natal signatures on benthic nests), a third natal source, Torrey Pines, appeared to contribute $\sim 6 \%$ of YOY. When natal origins of YOY were classified using larval reference data from discrete 2 wk bins, La Jolla remained the predominant source population within the study region, but the proportion of YOY initially predicted to be from La Jolla decreased from 97 to $82 \%$, while the proportion of YOY predicted to originate at Mission Point increased to $\sim 13 \%$. Using these 2 wk datasets to predict the natal origin of the same 8 YOY considered in the example above, the 7 individuals initially predicted to originate from La Jolla (using the entire 2008 data set), were predicted to originate from Mission Point, a site where empirical data showed that spawning was still occurring (Fig. 5).

\section{DISCUSSION}

The prevalence of otolith microchemistry as a tool for quantifying larval dispersal distances and population connectivity has grown since its first successful application (Swearer et al. 1999). However, we must strive to increase our understanding of the factors that may influence interpretation of these types of data, particularly when the impetus for many of these studies is to quantify the connectedness of spatially discontiguous populations, in attempts to better the effectiveness of spatial management of marine resources. The findings of this study suggest that if resource managers do not have sufficient data to accurately pair the life history of focal species with data describing population connectivity, conservation efforts may be inadvertently misdirected. For example, if data from this study were viewed holistically and the entire 2008 data set were utilized to identify source populations, 1 of the 3 source populations, namely Torrey Pines, would not have been identified. In addition, the relative importance of Mission Point, a location that supplied YOY to reefs 15 to $50 \mathrm{~km}$ away, may have been downplayed or even overlooked by stakeholders during the site-selection process.

If otolith microchemistry is to be used as a tool for inferring population connectivity, then ion uptake must be regulated by environmental rather than physiological factors (for a recent in-depth discussion, see Elsdon et al. 2008). Laboratory studies have started to shed light on which ions are regulated primarily by environmental parameters, and as such are the most appropriate for utilizing otolith microchemistry to address questions regarding population connectivity. Bath et al. (2000) showed that otolith incorporation of $\mathrm{Sr}$ and $\mathrm{Ba}$ is proportional to concentrations found in ambient waters. In a complementary study examining the relative importance of ambient water chemistry and diet in otolith chemical composition, Walther \& Thorrold (2006) showed that the majority of Sr and Ba ions comprising otoliths are regulated by surrounding water chemistry (83\% and $98 \%$, respectively), further suggesting that otolith microchemistry of these ions reflects ambient water chemistry. 


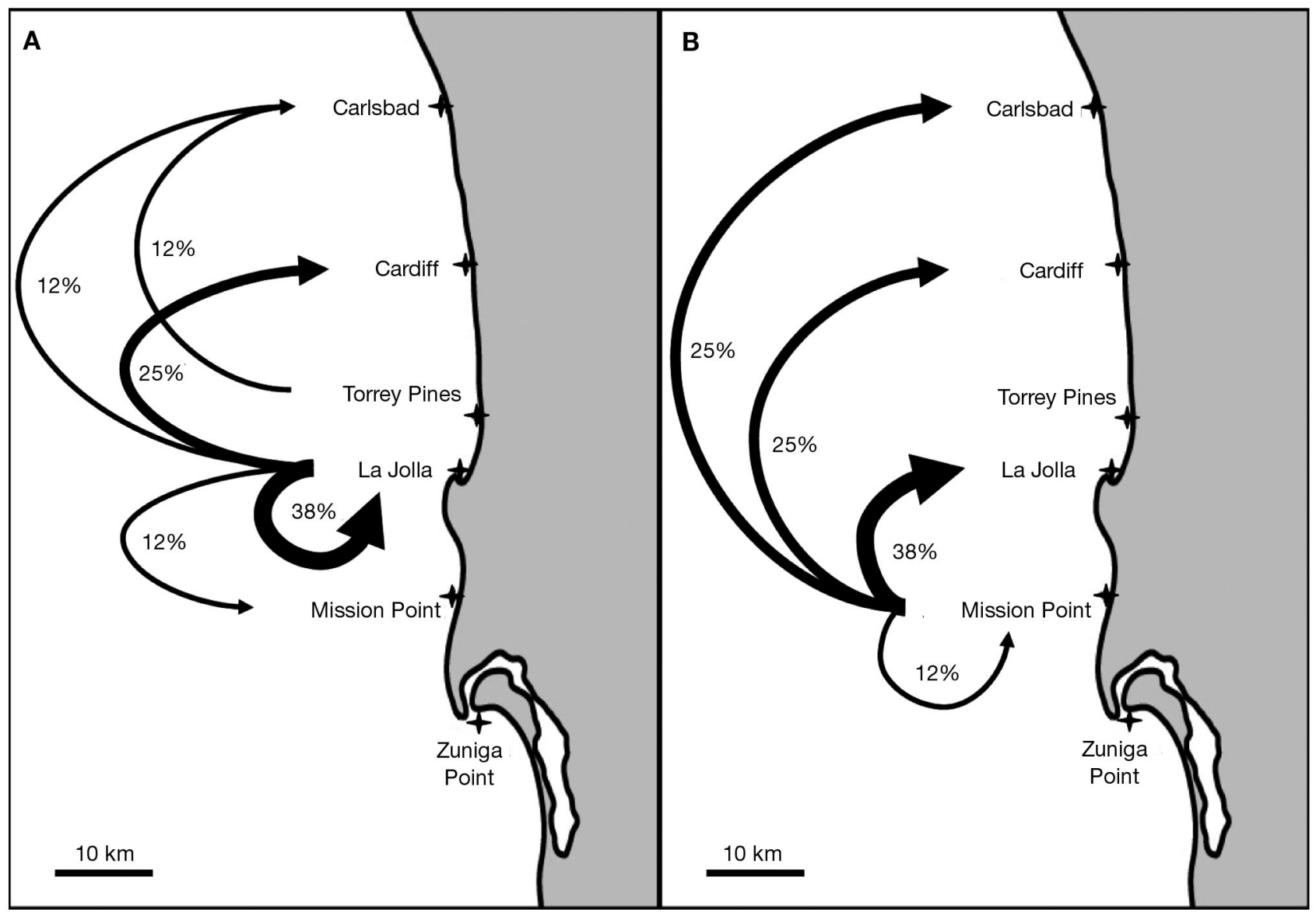

Fig. 5. Hypsypops rubicundus. Natal classification of 8 young-of-the-year (YOY) fish that were acquiring elemental signatures between 1 and 15 August 2008 using data spanning (A) the entire 2008 spawning season or (B) 1 to 15 August. Numbers indicate the proportion of YOY dispersing between 2 reefs. Arrows indicate directionality of dispersal, and the thickness of each arrow is proportional to the number of YOY dispersing. Stars indicate sampling sites

In an examination of interannual variability of otolith microchemistry, Walther \& Thorrold (2009) found that in order to successfully utilize otolith microchemistry to identify natal origins of American shad Alosa sapidissima, one must be aware of how variable microchemistry is on interannual time scales. The authors suggested that if considerable interannual variability exists, efforts must be made to accurately match microchemical data from larval fish to the cohort of interest. The present study builds upon the work of Walther \& Thorrold (2009) by showing that efforts must also be made to understand the intra-annual variability in otolith microchemistry, particularly for those species with protracted spawning seasons. However, in a comparison of 2 mo of Pagrus auratus (Sparidae) otolith microchemistry data from southeastern Australia, Hamer et al. (2003) determined that intra-annual (i.e. monthly-scale) chemical variability spanning the February to March recruitment season did not influence the classification accuracy of adults to their juvenile origin, and hence temporal mismatches did not influ- ence conclusions regarding connectivity patterns. In Hamer et al. (2003), within-year differences in classification success were driven primarily by Ba. The different conclusions being drawn between this and the present study may stem from the environmental history of the study organisms. P. auratus spends its early life in estuarine inlets prior to migrating to open-coast habitat, while Hypsypops rubicundus spends its entire life along the open coast. The strength of the Ba 'signal' incorporated into the otolith during this early juvenile estuarine phase, as evidenced by its preponderance in driving discrimination among inlets being studied by Hamer et al. (2003) appears to override the input of other elements comprising the otolith. However, for $H$. rubicundus, and perhaps for other species inhabiting open-coast regions, the relative importance of individual elements enabling discrimination among sites, in part due to a lack of this estuarine period, may mean that more high-resolution sampling (relative to the species in question) is necessary to adequately resolve connectivity patterns. 
While we continue to refine our use of this tool, generalizations regarding connectivity patterns remain few, with many differences among taxa and geographic locales. The present study addresses the challenges associated with and the necessity for understanding how microchemical fingerprints of reefs vary over time. For studies to accurately assess patterns of population connectivity and estimate larval dispersal distances, efforts must be made to collect and analyze samples spanning the entire spawning season of the species in question. Trace elemental fingerprints derived from otolith microchemical data reported here change over time scales ranging from weeks to months. These data emphasize challenges faced by scientists and resource managers using otolith microchemistry to quantify connectivity among marine populations inhabiting open coastlines, and show the extent of data collection necessary to capture the intra-annual temporal and spatial variability that occurs in otolith microchemistry. Without this knowledge, estimates of dispersal distance and population connectivity can perhaps be viewed best as first-order approximations of reality, and should be interpreted with caution.

Key to successful natal assignment is matching empirical data collection efforts to the natural history of the organism in question. In the present study, embryonic Hypsypops rubicundus incorporated their natal signatures over a $2 \mathrm{wk}$ benthic period prior to dispersing in the pelagic realm. For H. rubicundus, 2 wk was the most appropriate time scale at which to bin data. However, if the species in question was incorporating its natal signatures over a $30 \mathrm{~d}$ or $7 \mathrm{~d}$ period, perhaps the most appropriate scale at which to collect samples and bin data would differ.

The results of this study suggest 2 things: (1) the chemical compositions of otoliths collected more closely in space and time tend to be more similar, and (2) the spatial chemical variability, while statistically significant, cannot be used to assess connectivity patterns without an understanding of the temporal changes that occur in otolith microchemistry.

\section{CONCLUSIONS}

In ecology it has often been said that one must ask questions at the appropriate spatial and temporal scale (e.g. Levin 1992). In this instance, it has been shown that efforts must be made not only to ask questions at the appropriate scale, but to design studies at spatial and temporal scales relevant to the natural history of the organism of interest. To understand the role of dispersal in population dynamics, particularly for species approximately described as metapopulations due to dispersive developmental stages connecting spatially discontiguous habitat patches, this can be a daunting task. If the dispersal stage spans periods of several months, or if the spawning period is greatly protracted, as is the case for numerous marine species, the use of otolith microchemistry to quantify population connectivity may remain a tremendous logistical challenge.

The primary goal of the present study was to demonstrate that changes in otolith microchemistry occur over the course of an extended spawning season, and that these changes could result in the 'confusion' of one reef for another (as the ANOSIM data showed more than a third of the time). These temporal changes in reef-specific chemical fingerprints could influence an investigator's ability to accurately assess natal origin, larval dispersal distances, and connectivity patterns. This suggests that regardless of the forces influencing otolith microchemistry over a spawning season, having empirical data describing the biology of the species in question is invaluable and necessary to accurately quantify population connectivity using microchemical methods.

Acknowledgements. This work was funded by a United States Environmental Protection Agency Science to Achieve Results (STAR) fellowship; an NSF IGERT fellowship; a University of California CEQI fellowship; a Moore Family Foundation grant awarded by the Center for Marine Biodiversity and Conservation, Scripps Institution of Oceanography; a PADI Foundation grant; a Mia J. Tegner coastal ecology grant; and a California Seagrant Traineeship awarded to me. I thank L. Levin and my dissertation committee members for support, advice, and numerous helpful comments in the writing of this paper. I thank members of the Levin Laboratory, E. Johnstone, E. Kisfaludy, M. Stukel, C. Tanner, and numerous dive buddies for help with sample collections; L. Rasmussen for access to unpublished ADCP data; and P. E. Parnell for benthic survey data. Special thanks go to G. Paradis for help with otolith analyses.

\section{LITERATURE CITED}

Allen GR (1991) Damselfishes of the world. Mergus Publishers, Melle

Barbee NC, Swearer SE (2007) Characterizing natal source population signatures in the diadromous fish Galaxias maculatus, using embryonic otolith chemistry. Mar Ecol Prog Ser 343:273-282

Bath GE, Thorrold SR, Jones CM, Campana SE, McLaren JW, Lam JWH (2000) Strontium and barium uptake in aragonitic otoliths of marine fish. Geochim Cosmochim Acta 64: 1705-1714

Becker BJ, Fodrie FJ, McMillan PA, Levin LA (2005) Spatial and temporal variation in trace elemental fingerprints of mytilid mussel shells: a precursor to invertebrate larval tracking. Limnol Oceanogr 50:48-61

Clarke TA (1970) Territorial behavior and population dynamics of a pomacentrid fish, the garibaldi, Hypsypops rubicunda. Ecol Monogr 40:189-212

Clarke KR (1993) Non-parametric multivariate analyses of changes in community structure. Aust J Ecol 18:117-143 
Clarke KR, Gorley RN (2006) Primer V6: user manual/tutorial. PRIMER-E, Plymouth

Clarke KR, Warwick RM (2001) Change in marine communities: an approach to statistical analysis and interpretation, 2nd edn. PRIMER-E, Plymouth

Clarke LM, Walther BD, Munch SB, Thorrold SR, Conover DO (2009) Chemical signatures in the otoliths of a coastal marine fish, Menidia menidia, from the northeastern United States: spatial and temporal differences. Mar Ecol Prog Ser 384:261-271

Cowen RK, Gawarkiewicz G, Pineda J, Thorrold SR, Werner FE (2007) Population connectivity in marine systems: an overview. Oceanography 20:14-21

Elsdon TS, Wells BK, Campana SE, Gillanders BM and others (2008) Otolith chemistry to describe movements and lifehistory parameters of fishes: hypotheses, assumptions, limitations and inferences. Oceanogr Mar Biol Annu Rev 46:297-330

Fodrie FJ, Levin LA (2008) Linking juvenile habitat utilization to population dynamics of California halibut. Limnol Oceanogr 53:799-812

Hamer PA, Jenkins GP, Gillanders BM (2003) Otolith chemistry of juvenile snapper Pagrus auratus in Victorian waters: natural chemical tags and their temporal variation. Mar Ecol Prog Ser 263:261-273

Hubbs CL (1960) The marine vertebrates of the outer coast. Syst Zool 9:134-147

Levin SA (1992) The problem of pattern and scale in ecology: the Robert H. MacArthur Award lecture. Ecology 73: 1943-1967

Limbaugh C (1964) Notes on the life history of two Californian pomacentrids: garibaldis, Hypsypops rubicunda (Girard) and blacksmiths, Chromis punctipinnis (Cooper). Pac Sci $18: 41-50$

Love M (1996) Probably more than you want to know about the fishes of the Pacific coast, 2nd edn. Really Big Press, Santa Barbara, CA

Miller DJ, Lea RN (1972) Guide to the coastal marine fishes of California. California Department of Fish and Game, Sacramento, CA

Moser H (1996) The early stages of fishes in the California Current region. California Cooperative Oceanic Fisheries Investigations Atlas 33, La Jolla, CA

Patterson WF, Cowan JH, Wilson CA, Chen Z (2008) Temporal and spatial variability in juvenile red snapper otolith elemental signatures in the northern Gulf of Mexico. Trans Am Fish Soc 137:521-532

Rasmussen LL, Cornuelle BD, Levin LA, Largier JL, Di Lorenzo E (2009) effects of small-scale features and local

Editorial responsibility: Hans Heinrich Janssen, Oldendorf/Luhe, Germany wind forcing on tracer dispersion and estimates of population connectivity in a regional scale circulation model. J Geophys Res 114:C01012. doi:10.1029/2008JC004777

Ruttenberg BI, Warner RR (2006) Spatial variation in the chemical composition of natal otoliths from a reef fish in the Galapagos Islands. Mar Ecol Prog Ser 328:225-236

Ruttenberg BI, Hamilton SL, Hickford MJH, Paradis GL, Sheehy MS, Standish JD, Ben-Tzvi O, Warner RR (2005) Elevated levels of trace elements in cores of otoliths and their potential use as natural tags. Mar Ecol Prog Ser 297: 273-281

Ruttenberg BI, Hamilton SL, Warner RR (2008) Spatial and temporal variation in the natal otolith chemistry of a Hawaiian reef fish: prospects for measuring population connectivity. Can J Fish Aquat Sci 65:1181-1192

> Shanks AL, Eckert GL (2005) Population persistence of California current fishes and benthic crustaceans: a marine drift paradox. Ecol Monogr 75:505-534

Sikkel PC (1988) Factors influencing spawning site choice by female garibaldi Hypsypops rubicundus (Pisces: Pomacentridae). Copeia 1988:710-718

Sikkel PC (1989) Egg presence and developmental stage influence spawning site choice by female garibaldi. Anim Behav 38:447-456

> Standish JD, Sheehy M, Warner RR (2008) Use of otolith natal elemental signatures as natural tags to evaluate connectivity among open-coast fish populations. Mar Ecol Prog Ser 356:259-268

> Swearer SE, Caselle JE, Lea DW, Warner RR (1999) Larval retention and recruitment in an island population of a coral-reef fish. Nature 402:799-802

Thorrold SR, Zacherl DC, Levin LA (2007) Population connectivity and larval dispersal using geochemical signatures in calcified structures. Oceanography 20:80-89

Walther BD, Thorrold SR (2006) Water, not food, contributes the majority of strontium and barium deposited in the otoliths of a marine fish. Mar Ecol Prog Ser 311: $125-130$

- Walther BD, Thorrold SR (2009) Inter-annual variability in isotope and elemental ratios recorded in otoliths of an anadromous fish. J Geochem Explor 102:181-186

Warner RR, Swearer SE, Caselle JE, Sheehy M, Paradis G (2005) Natal trace-elemental signatures in the otoliths of an open-coast fish. Limnol Oceanogr 50:1529-1542

White JW, Ruttenberg BI (2007) Discriminant function analysis in marine ecology: some oversights and their solutions. Mar Ecol Prog Ser 329:301-305

Zar JH (1999) Biostatistical analysis, 4th edn. Prentice-Hall Upper Saddle River, NJ

Submitted: June 1, 2010; Accepted: November 17, 2010

Proofs received from author(s): February 1, 2011 